\title{
Studies on Methacrylic Acid Modified Poly(ester amide) Derived from Phthalic Acid and Fatty Amide Diol of Melia Azedarch Seed Oil
}

\author{
SAGEER AHAMAD, S. A. AHMAD and A. HASNAT* \\ Natural Product and Polymer Research Laboratory, Department of Chemistry, G.F. College \\ (M.J.P. Rohilkhand University), Shahjahanpur, U.P. India \\ hasnatgfc@rediffmail.com
}

Received 28 May 2016/ Accepted 26 June2016

\begin{abstract}
The present work designed to utilize Melia azedarach seed oil (MASO), a renewable resource in the synthesis of methacrylic acid modified poly(ester amide) resins (MAMAPEA). The poly(ester amide) (MAPEA) was synthesized by the polycondensation reaction between fatty amide diol of MASO obtained by the aminolysis with diethanol amine and phthalic acid. The MAPEA reacted with methacrylic acid in different per hundred of resin (phr) to obtain MAMAPEA polymeric resins. The polymeric resins were characterized by measuring the physicochemical properties and spectral analyses. The Physicomechanical and corrosion/chemical resistance performances of the MAMAPEA containing different phr of methacrylic acid evaluated to find out the optimum amount of methacrylic acid. It has been observed that MAMAPEA-20 contain 20 phr of methacrylic acid shows the best performance among different MAMAPEA polymeric resins.
\end{abstract}

Keywords: Melia azedarach seed oil, Methacrylic acid, Poly(ester amide), Coating materials

\section{Introduction}

Synthesis and characterization of valuable polymeric material from renewable resources has attracted the attention of academia and researchers throughout the world ${ }^{1-3}$. This is due to exhaustion of world petrochemical stock and environmental concern both ${ }^{4,5}$. In present scenario it is required to innovate the useful materials which are not only economical but it must be environment friendly. Numerous polymers for various applications have been developed by using renewable resource like $\operatorname{starch}^{6}, \operatorname{protein}^{6,7}, \operatorname{lignin}^{8}$ and vegetable oil ${ }^{8,9}$ etc. They have got many fold industrial applications such as plasticizer adhesive coatings, packaging materials and many others.

Among various renewable resources vegetable oils obtained from the different seeds represent a promising class of raw material for the polymer industry ${ }^{1}$. Common seed oil such as linseed, sunflower, castor, soybean largely used in the synthesis of polymer like alkyd ${ }^{10}$, epoxies $^{10}$, polyurethanes ${ }^{11}$, interpenetrating polymer networks (IPN $)^{11,12}$, poly $(\text { ester amide })^{10,13}$ 
and many others. These polymers are extensively used as coatings adhesives, insulators and biomedical structures. However, among aforesaid traditional oils some of them posses medicinal values and are edible too. Therefore, it is important to explore the blessings of nature, utilized the non-edible oils in the synthesis of monomers and polymers. Melia azedarach belongs to the family meliaceae largely cultivated due to its ornamental look and valuable wood ${ }^{14}$. The seeds of plants contain about $40 \mathrm{wt} \%$ triglyceride oil with sufficiently high iodine value which confer the film formation ability to the end product ${ }^{14,15}$. Poly(ester amide) resins obtained from different seeds oil are amide modified alkyds reported for improved performances over traditional alkyds in terms of hardness, water vapor resistance and chemical/corrosion resistance ability in many service conditions ${ }^{13,16}$. However, high baking temperature required for cross-linking and low load bearing capacity hampers its versatile utilization ${ }^{13}$. Incorporation of metals, metalloids, and acrylic monomers in the oil based polymer reduces the curing temperature notably as well as also improve the scratch hardness values ${ }^{8,17}$. In this work we report the synthesis and characterization of methacrylic acid modified poly(ester amide) obtained by the polycondensation of fatty amide diol of Melia azedarach and phthalic acid with the objective to provide more practicable application to meager utilized Melia azedarach seed oil. The synthesized resins were characterized by analytical and spectral studies. Physicomechanical and chemical/corrosion resistance performance of the polymeric films were also investigated.

\section{Experimental}

Melia azedarach seed oil (MASO) was extracted from the crushed and dried seeds of Melia azedarach collected from the different places of the Shahjahanpur through the Soxhlet apparatus by using petroleum ether as a solvent $\left(60-80{ }^{\circ} \mathrm{C}\right)$. Phthalic acid, diethyl ether, methacrylic acid and xylene were purchased from Merck. Diethanol amine of analytical grade procured from the S.D. Fine Chemicals, India and was distilled under reduced pressure before use.

\section{Syntheses}

N,N-bis(2-hydroxyethyl) Melia azedarach oil fatty acid (HEMAFA) and Melia azedarach Poly(ester amide) (MAPEA)

HEMAFA and MAPEA using phthalic acid as a dibasic acid were synthesized as per reported methods of aminolysis of vegetable oils and polycondensation polymerization ${ }^{17}$.

\section{Methacrylic acid modified poly(ester amide) (MAMAPEA)}

Poly(ester amide) of Melia azedarach seed oil (MAPEA) dissolved in xylene placed in a four necked round bottom flask fitted with mechanical stirrer, condenser, nitrogen inlet tube and a thermometer. The contents were heated up to $140{ }^{\circ} \mathrm{C}$, then methacrylic acid (MA) in different per hundred of resin (phr) and bezoyl peroxide (0.1-wt\% of MA) added slowly in the reaction mixtures. The reaction mixtures were allowed continue at same temperature under stirring for two hours to obtain MAMAPEA polymeric resins as end products. On completion of reactions, the products were allowed cool down at room temperature under string. The excess of xylene was removed under reduced pressure in a rotary evaporator.

\section{Characterization}

Physicochemical characterizations such as specific gravity, refractive index, viscosity, acid value, iodine value and saponification value of the polymeric resins were carried out as per 
standard reported laboratory methods ${ }^{4,6,18}$. The structural elucidation of the polymer samples were carried out by spectral analyses. FT-IR spectrum of the MAMAPEA was recorded on FT-IR spectrophotometer (Perkin-Elmer Cetus instruments, Norwalk CT, USA) using a $\mathrm{NaCl}$ cell. ${ }^{1} \mathrm{H}$ NMR and ${ }^{13} \mathrm{C}$ NMR spectra were recorded on JEOL GSX $300 \mathrm{MHz}$ FX-1000 spectrometer using deuterated chloroform as a solvent where as tetramethylsilane (TMS) as an internal standard.

\section{Preparation of coatings}

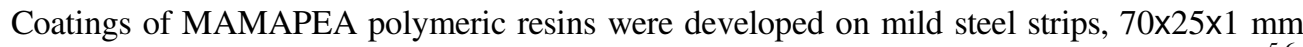

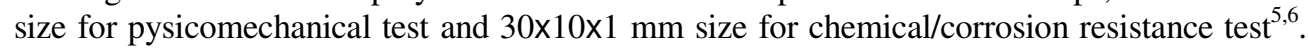
The mild steel strips were polished on various grades of silicon carbide papers, washed with distilled water and finally degreased with alcohol and carbon tetrachloride. They were dried under vacuum for several hours. The coatings were developed on these specimens by brush technique using a solution of $60 \mathrm{wt} \%$ of polymeric resins. Coated samples were baked at $160{ }^{\circ} \mathrm{C}$ for 30 minutes. Elcometer (Model 345) was used to measure the coating thickness and were found between $75 \pm 5 \mu \mathrm{m}$. The coated specimens were subjected for bending test on conical mandrel, the resistance to scratch hardness (BS 3900), and impact resistance (IS: 101 part 5/s. $31988)$ tests. Chemical and corrosion resistance tests of the polymeric films were carried out in water, acid $(5 \mathrm{wt} \% \mathrm{HCl})$, alkali $(5 \mathrm{wt} \% \mathrm{NaOH})$ and salt $(3.5 \mathrm{wt} \% \mathrm{NaCl})$ by placing them in 3 in diameter porcelain dishes, in aforementioned media and examinations were carried out at regular intervals until coating showed visual evidence of softening, deterioration in gloss, discoloration or weight loss (Table 1).

\section{Results and Discussion}

Figure 1 depicts the reaction scheme for the synthesis of MAPEA and MAMAPEA. The HEMAFA obtained by aminolysis of MASO undergo polycondensation reaction with phthalic acid to produce MAPEA. MAPEA resin was then treated with methacrylic acid in different phr (Table 1) to obtain a series of MAMAPEA polymeric resins. Methacrylic acid grafted at allylic position of non-conjugated fatty amide chain, the free radicals serve to modify the growth of acrylic acid chain though chain transfer mechanism ${ }^{13}$. Table 1 indicates that, iodine values decreases gradually on increasing the amount of methacrylic acid (phr) but remain the same for same amount of MAPEA in the reactions. These results show that grafting occur at allylic position without altering the unsaturation of fatty amide.

The FT-IR spectrum of MAMAPEA shows the broad band at $3342 \mathrm{~cm}^{-1}$ for the O-H stretching vibration, band at $3064 \mathrm{~cm}^{-1}$ for Ar-H, bands at $2974 \mathrm{~cm}^{-1}$ and $2868 \mathrm{~cm}^{-1}$ for $\mathrm{CH}_{2}$ asymmetric and symmetric stretching vibrations respectively ${ }^{19}$. The bands for carbonyl of repeating ester linkages, carboxylic acid and amide are appear at $1764 \mathrm{~cm}^{-1}$, $1705 \mathrm{~cm}^{-1}$ and $1654 \mathrm{~cm}^{-1}$ respectively. The characteristic bands of aromatic ring appears at $1598,774 \mathrm{~cm}^{-1}$. ${ }^{1} \mathrm{HNMR}$ spectrum of MAMAPEA shows the peaks at $\delta=7.40-7.62$ ppm due to aromatic protons of phthalic acid while proton of double bonded carbons appear at $\delta=5.36-5.46 \mathrm{ppm} . \mathrm{CH}_{2}$ attached to nitrogen of amide appear at $\delta=3.72-4.02$ $\mathrm{ppm}$, where as allylic methylene and methine protons appear at $\delta=2.42$ and $2.74 \mathrm{ppm}$ respectively ${ }^{19}$. Sharp peak for $\mathrm{CH}_{2}$ adjacent to ester appears at $\delta=2.10 \mathrm{ppm}$, different $\mathrm{CH}_{2}$ of fatty amide chain appear as multiplet at $\delta=1.28-1.48 \mathrm{ppm}$ and proton of terminal methyl group at $\delta=0.92 \mathrm{ppm} .{ }^{13} \mathrm{C}$ NMR spectrum show the peaks at $\delta=176.8 \mathrm{ppm}$, $\delta=174.6 \mathrm{ppm}$ and $\delta=164.2 \mathrm{ppm}$ for the carbonyl of carboxylic acid, ester and amide ${ }^{19}$. Closely spaced peaks at $\delta=132.8-129.2 \mathrm{ppm}$ due to carbon of aromatic ring ${ }^{20}$. Double 
bonded carbons appear at $\delta=132.2-128.8 \mathrm{ppm}$ where as carbons of allylic methine and methylene appears at $\delta=51.8$ and $\delta=44.2$ ppm respectively ${ }^{19,20}$. Peaks for chain $\mathrm{CH}_{2}$ of fatty amide appears at $\delta=29.2-21.8 \mathrm{ppm}$ while carbon of terminal methyl group appears at $\delta=14.2 \mathrm{ppm}$.

Table 1. Physicochemical, mechanical and chemical/corrosion resistance properties of MAMAPEA polymeric resins

\begin{tabular}{|c|c|c|c|c|c|}
\hline Resin $\operatorname{code}{ }^{*} \rightarrow$ & $\begin{array}{l}\text { MAMAPEAP- } \\
5\end{array}$ & $\begin{array}{c}\text { MAMAPEAP- } \\
10\end{array}$ & $\begin{array}{l}\text { MAMAPEAP- } \\
15\end{array}$ & $\begin{array}{c}\text { MAMAPEAP- } \\
20\end{array}$ & $\begin{array}{l}\text { MAMAPEAP- } \\
25\end{array}$ \\
\hline \multicolumn{6}{|c|}{ Physicochemical analyses } \\
\hline Color value & 8 & 7 & 7 & 6 & 6 \\
\hline Specific gravity & 0.970 & 0.978 & 0.980 & 0.982 & 0.984 \\
\hline $\begin{array}{l}\text { Refractive } \\
\text { index }\end{array}$ & 1.5082 & 1.5086 & 1.5092 & 1.5134 & 1.5142 \\
\hline $\begin{array}{l}\text { Inherent } \\
\text { viscosity } \mathrm{dL} / \mathrm{g} \text { ) }\end{array}$ & 0.722 & 0.728 & 0.736 & 0.746 & 0.748 \\
\hline Iodine value & 48.44 & 48.20 & 44.22 & 41.42 & 39.26 \\
\hline \multicolumn{6}{|c|}{ Physicomechanical properties } \\
\hline $\begin{array}{l}\text { Bending test } \\
\text { (1/8 in) }\end{array}$ & Pass & Pass & Pass & Pass & Fail \\
\hline $\begin{array}{l}\text { Gloss } \\
\text { at } 45^{\circ}\end{array}$ & 36 & 42 & 52 & 58 & 58 \\
\hline $\begin{array}{l}\text { Impact } \\
\text { resistance } \\
\text { (lb/in) }\end{array}$ & 100 & 150 & 200 & 200 & 200 \\
\hline $\begin{array}{l}\text { Scratch } \\
\text { hardness }(\mathrm{kg})\end{array}$ & 1.0 & 1.5 & 2.5 & 3.0 & 3.0 \\
\hline
\end{tabular}

\begin{tabular}{|c|c|c|c|c|c|}
\hline \multicolumn{6}{|c|}{ Chemical/corrosion resistance ${ }^{* *}$} \\
\hline $\begin{array}{l}\mathrm{H}_{2} \mathrm{O} \\
\text { (10 days) }\end{array}$ & $\mathrm{D}$ & $\mathrm{E}$ & $\mathrm{E}$ & $\mathrm{E}$ & $\mathrm{D}$ \\
\hline $\begin{array}{l}\mathrm{HCl}(5 \mathrm{wt} \%) \\
10 \text { days }\end{array}$ & $\mathrm{C}$ & $\mathrm{E}$ & $\mathrm{E}$ & $\mathrm{E}$ & $\mathrm{D}$ \\
\hline $\begin{array}{l}\mathrm{NaOH}(5 \mathrm{wt} \%) \\
2 \mathrm{~h}\end{array}$ & A & $\mathrm{C}$ & $\mathrm{D}$ & $\mathrm{D}$ & $\mathrm{C}$ \\
\hline $\begin{array}{l}\mathrm{NaCl}(5 \mathrm{wt} \%) \\
10 \text { days }\end{array}$ & $\mathrm{C}$ & $\mathrm{D}$ & $\mathrm{E}$ & $\mathrm{E}$ & $\mathrm{D}$ \\
\hline
\end{tabular}




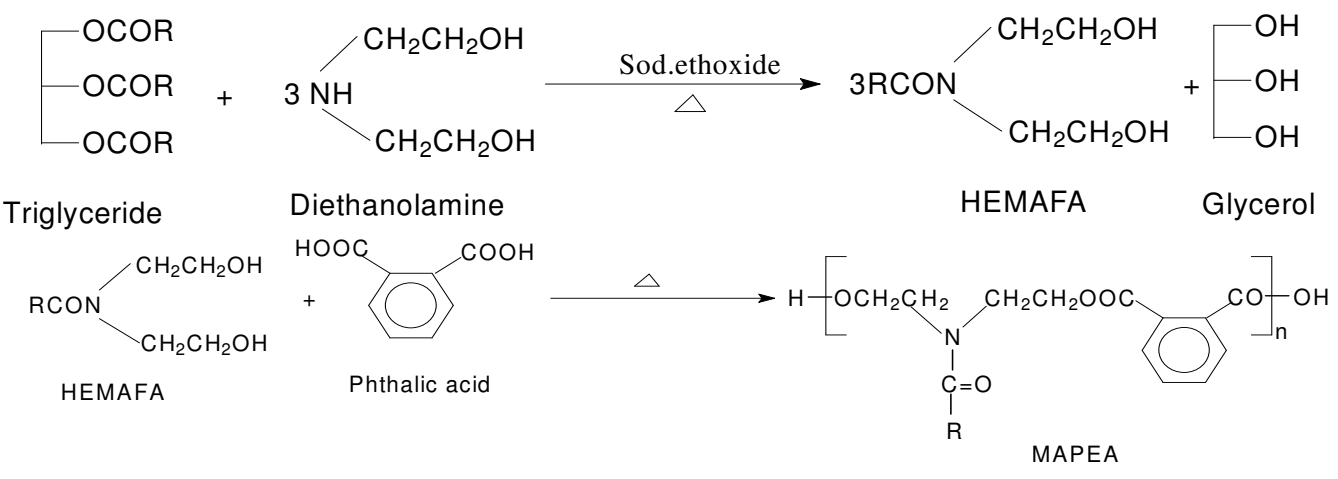

$R=$ Long alkyl chain of fatty aid of oil

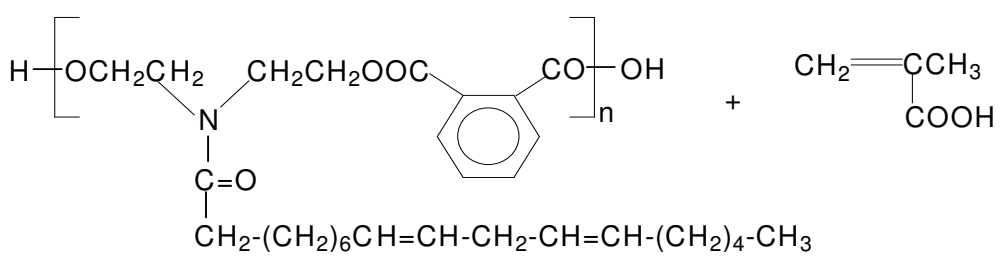

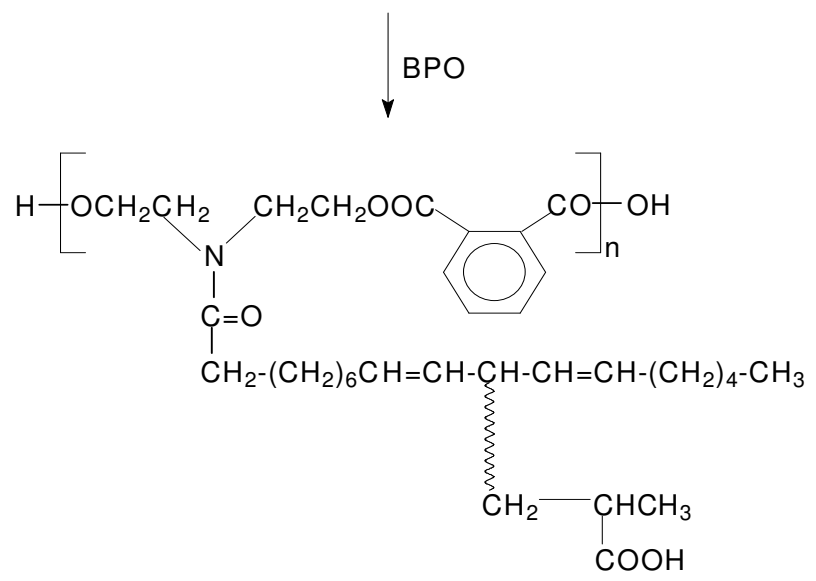

Figure 1. Reaction scheme for the formation of MAMAPEA

\section{Coating properties}

The films of MAMAPEA polymeric resins embedded with different phr of MA (Table 1) prepared on the mild steel strips to study the physicomechanical and chemical/corrosion resistance properties. Resistance to scratch hardness values were found to be improved on increasing the MA content up to $20 \mathrm{phr}$. This is reasonably due to increase of pendent carboxylic groups which are responsible for cross-linking through physical as well as chemical phenomenon ${ }^{21}$. However, after this wt\% loading of MA improvement was negligible. All the coated samples were found to show the good impact resistance, more than $100 \mathrm{lb} / \mathrm{in}$, reasonably due good adhesion of polymeric films with metal surface. On increasing the MA content this phenomenon was further improved up to the $20 \mathrm{phr}$. Beyond 
this loading of MA in the polymeric resins this property start to deteriorate, reasonably due to excessive cross-linking; which produces strain in the polymeric films causing brittleness. In addition to this it has been found that loading of MA above than 25 phr coating materials becomes viscous and more dilution of the system was required while applying on the specimens; dilute solution of coating materials loss their protection abilities as it leaves small pores while evaporation of solvent. Gloss values of polymeric films increases on increasing the amount of MA, which expected for acrylic based coating materials and formation of more dense structure. The polymeric films pass the bending test on $1 / 8$ conical mandrel up to the $20 \mathrm{phr}$ loading of MA, a characteristic of vegetable oil based coating materials. Table 1 reveals that chemical resistance performances of MAMAPEA improved up to $20 \mathrm{phr}$ loading of MA. MAMAPEA-20 among all MAMAPEA coating systems shows the best performance in aqueous, acidic and saline environments. On perusal of Table 1 it has been found that chemical resistance performance of the polymeric films start to deteriorate beyond this loading of MA. This is reasonably due to high cross-linking density make the film brittle and also causes shrinkage of the film at edges ${ }^{11,12,21}$.

\section{Conclusion}

Synthesis of methacrylic acid modified poly(ester amide) resins from Malea azedarach seed oil provides a new way to utilize a non-edible and annually renewable resource in developing coating materials. The synthesized resins were characterized by taking physicochemical analyses as well as by spectral studies. Physicomechanical and corrosion/chemical resistance properties of the polymeric films containing different phr of methacrylic acid were investigated. MAMAPEA-20 containing $20 \mathrm{phr}$ methacrylic acid shows the best performances among various MAMAPEA polymeric resins. The study reveals that syntheses of MAMAPEA polymeric resins provide a valuable route for the utilization of MASO annually rot away.

\section{Acknowledgement}

The authors would like to thank the authorities of G. F. College, Shahjahanpur, UP, India for providing necessary facilities for carrying out this study and Mr. A.Wahab for valuable suggestion.

\section{References}

1. Islam M R, Beg M D H and Jamari S S, J Appl Polym Sci., 2014, 131(18), 4078740799; DOI:10.1002/app.40978

2. Zafar F, Ashraf S M and Ahmad S, Reactive Functional Polym., 2007, 67(10), 928935; DOI:10.1016/j.reactfunctpolym.2007.05.018

3. Imran G, Ahamad S, Altaf I and Ahmad S A, Chem Sci Trans., 2015, 4(4), 10071012; DOI:10.7598/cst2015.1103

4. Ahmad S, Ashraf S M, Hasnat A and Noor A, Indian J Chem Technol., 2001, 8, 176180.

5. Ahmad S, Ashraf S M and Alam M, J Macromolecular Sci Part A: Pure Appl Chem., 2006, 43(4), 773-783; DOI:10.1080/10601320600598886

6. Ahmad S, Ashraf S M, Hasnat A, Yadav S and Jamal A, J Appl Polym Sci., 2001, 82(8), 1855-1865; DOI:10.1002/app.2029

7. Lochab B, Varma I K and Bijwe J, Adv Mater Physic Chem., 2012, 2, 221-225; DOI:10.4236/ampc.2012.24B056

8. Sounders K J, Organic Polymer Chemistry, $2^{\text {nd }}$ Edn., (Chapman and Hall, USA) 1988. 
9. Ahmad S, Ashraf S M, Naqvi F, Yadav S and Hasnat A, Prog Org Coat., 2003, 47(2), 95-102; DOI:10.1016/S0300-9440(03)00015-8

10. Ahmad S, Ashraf S M, Naqvi F, Yadav S and Zafar F, J Macromolecular Sci Part A: Pure Appl Chem., 2006, 43(9), 1409-1419; DOI:10.1080/10601320600820280

11. Ahmad S, Ashraf S M, Sharmin E, Zafar F and Hasnat A, Prog Crystal Growth Charact Mater., 2002, 45(1-2), 83-88; DOI:10.1016/S0960-8974(02)00031-1

12. Ahmad S, Ashraf S M, Kumar S, Alam M and Hasnat A, Indian J Chem Technol., 2005, 12, 193-197.

13. Guner F S, Yagci Y and Erciyes A T, Progress Polym Sci., 2006, 31(7), 633-670; DOI:10.1016/j.progpolymsci.2006.07.001

14. Ahmad S, Ashraf S M, Naqvi F, Yadav S and Hasnat A, J Polym Mater., 2001, 18, 53-60.

15. Ambastha S P, Useful Plants of India, CSIR, New Delhi, 1986.

16. Ahamad S, Ahmad S A and Hasnat A, Chem Sci Trans., 2015, 4(4), 1047-1053; DOI:10.7598/cst2015.1105

17. Ahamad S, Imran G, Ahmad S A and Hasnat A, Orient J Chem., 2015, 31(2), 11691173 .

18. Ahmad S, Haque M M, Ashraf S M and Ahmad S, Eur Polymer J., 2004, 40(9), 2097-2104; DOI:10.1016/J.Eurpolymj.2004.05.013

19. Silverstein R M, Bassler G C and Morril T C, Spectroscopic Identification of Organic Compounds, $5^{\text {th }}$ Edn., (John Wile y \& Sons, New York), 1991.

20. Pavia D L, Lampman G M, Kriz G S and Vyvyan J R, Spectroscopy, $5^{\text {th }}$ Edn., (Cengage Learning, India), 2011.

21. Zafar F, Ashraf S M and Ahmad S, Chem Chem Technol., 2008, 2(4), 285-293. 